\title{
Our Clinical Experiences on Pediatric Head Trauma Cases
}

\author{
Mustafa Efendioğlu, (i) Ezgi Akar, (i) Selin Tural Emon, Arif Tarkan Çalışaneller \\ Department of Neurosurgery, University of Health Sciences Turkey, Haydarpaşa Numune Health Application and Research Center, \\ Istanbul, Turkey
}

\begin{abstract}
Introduction: Head injury is an important cause of morbidity and mortality in the pediatric age group. In this study, we aim to share our experience in the management of childhood head trauma cases.

Methods: Data on the clinical, radiological and demographic characteristics of our children patient group who had head trauma followed by our clinic between the years of 2017 and 2019 were analyzed retrospectively in this study.

Results: $77.6 \%$ of the children fell from a height, $10.2 \%$ of them were vehicle accidents and $12.2 \%$ of them were isolated head trauma. $56.1 \%$ of children are between $0-2$ years old, $19.4 \%$ between 3-7 years old and $24.5 \%$ between $8-17$ years old. The rate of falling from height in children aged 0-2 years (96.4\%), 3-7 age (57.9\%) and 8-17 age (50\%) groups were significantly higher than children. GKS scores ranged from 4 to 15 , with an average of $14.63 \pm 1.58$ and a median of 15 . While $92.9 \%$ of the cases were mild head trauma, $5.1 \%$ of the cases were middle head trauma, and $2 \%$ were severe head trauma. Considering the findings of IT, Linear fracture was found in 49\%, epidural hematoma in 42.9\%, contusion in $21.4 \%$, subdural hematoma in $19.4 \%$, SAK in $14.3 \%$ and collapse fracture in $10.2 \%$. While $77.6 \%$ of the children did not have surgery, hematoma surgery was performed in 15.3\%, decompressive surgery in 3.1\%, hematoma and decompressive surgery in 4.1\%. There was an inverse, $50.5 \%$ and statistically significant correlation between the initial GCS score and blood sugar.

Discussion and Conclusion: Head trauma, which is a preventable cause of morbidity and mortality, is important in pediatric neurosurgery patient follow-up. Early diagnosis and treatment in these patients reduce many severe consequences from disabilities to death.
\end{abstract}

Keywords: Computerized tomography; morbidity; mortality; pediatric head trauma; prognosis.

$P$ ediatric head trauma is a common health problem in the pediatric age group and may cause significant morbidity and mortality in this age group [1]. Head traumas constitute $12 \%$ of the indications for admission to the hospital during childhood ${ }^{[2]}$. Because the children had heavier head mass and the thinner calvarium compared to adults, head traumas of the same severity may progress with more severe outcomes in children, and their long-term results may differ ${ }^{[2,3]}$. According to the severity of traumatic brain injury due to head trauma, head traumas are classified as mild, moderate and fatal ${ }^{[1,3]}$. In this classification, Glasgow coma scores (GCSs) of the patient at admission to the hospital are considered ${ }^{[4]}$.

Patients with GCS scores 14-15, 9-13, and 3-8 points are classified as having mild, moderate and severe-fatal brain injuries ${ }^{[4]}$. The causes of head injuries are similar all over the world and mostly preventable. For this reason, etiological and epidemiological studies in this area are important. In this study, we have compiled the etiological and clinical features of our pediatric patients admitted to our hospital due to head trauma in the light of current literature data.

Correspondence (İletişim): Ezgi Akar, M.D. Saglik Bilimleri Universitesi Hamidiye Tip Fakultesi, Haydarpasa Numune Saglik Uygulama ve Arastirma Merkezi, Beyin Cerrahisi Anabilim Dali, Istanbul, Turkey

Phone (Telefon): +90 2163868263 E-mail (E-posta): ezgiaycicek@gmail.com

Submitted Date (Başvuru Tarihi): 03.06.2020 Accepted Date (Kabul Tarihi): 03.06.2020

Copyright 2020 Haydarpaşa Numune Medical Journal

OPEN ACCESS This is an open access article under the CC BY-NC license (http://creativecommons.org/licenses/by-nc/4.0/) 


\section{Materials and Methods}

The clinical, radiological and demographic data of the 98 patients under the age of 18 who were admitted to the emergency department of our hospital with head trauma between 2017 and 2019 and followed up and treated by our clinic were retrospectively analyzed. Patients with spinal trauma and vital internal organ injuries were excluded from this study. According to the neurological examinations and computed tomography (CT) findings of the patients (computed brain tomography, fracture of the cranium bones, intracranial hemorrhage or edema), the decision to hospitalize these patients were made.

The decision for hospitalization was also made for patients with positive $\mathrm{CT}$ findings, patients with a defect detected in their neurological examination, and/or whose GCS scores were below 15 points, and cases with positive $C T$ findings even if their GCS scores were 15 points. The follow-up and treatment of cases with severe head trauma with GCS scores of $\leq 9$ points were performed in the intensive care unit, and the follow-up of patients with improvement in clinical findings was maintained in our service. Age, gender, GCS scores, causes of trauma, accompanying organ injuries, whether surgery was performed, CT findings, a surgical indication of patients undergoing surgery, duration of hospitalization, whether CPR was performed, need for intensive care follow-up, causes of mortality, blood glucose values at admission, and the relationship between admission GCS scores and blood glucose values were evaluated.

\section{Statistical Analysis}

For the statistical analysis of the results obtained in this study, IBM SPSS Statistics 22 (IBM SPSS, Turkey) programs were used. The suitability of the parameters to normal distribution was evaluated with the Shapiro- Wilks test. While evaluating the study data, in the comparison of qualitative statistical methods (mean, standard deviation, median, frequency), one-order chi-square test and Fisher- FreemanHalton test were used. Spearman's rho correlation analysis was used to examine the relationships between parameters that do not conform to normal distribution. Statistical significance was evaluated at the level of $p<0.05$.

\section{Results}

This study was carried out with 98 children including 58 (59.2\%) boys and $40(40.8 \%)$ girls, whose ages ranged from one month to 17 years. The mean age of the study population was $4.73 \pm 5.58$ years (median: 2 years). Blood glucose values ranged from 62 to $321 \mathrm{mg} / \mathrm{dL}$ (mean \pm SD: $112.41 \pm 32.04 \mathrm{mg} / \mathrm{dL}$; median: $106 \mathrm{mg} / \mathrm{dL}$ ) (Table 1). The respective proportion of study participants were $0-2$ (56\%)

\section{3-7 (19.4\%), and 8-17 (24.5\%) years old.}

A statistically significant difference existed between age groups in terms of trauma rates $(p=0.000 ; p<0.05)$. The rate of trauma in children aged $0-2$ years was significantly higher than children aged 3-7 and 8-17 years $(p 1=0.000$; $\mathrm{p} 2=0.000$; and $\mathrm{p}<0.05$, respectively).

Table 1. Distribution of the study parameters

\section{n}

Age (year)

$0-2$

3-7

8-17

Gender

Male

Female

Type of trauma

Fall from a height

Traffic accident

Isolated head trauma

Multitrauma

Yes

No

GCS

Mild

Moderate

Severe

Pupillary response

Isocoric

Anisocoric

CPR

Yes

No

Cerebral CT

$\mathrm{SAH}$

Subdural Hematoma

Epidural Hematoma

Linear Skull Fracture

Depressed Skull Fracture

Contusion

Surgery

No

Hematoma surgery

Decompressive surgery

Hematoma+Decompressive

Intensive Care

Yes

No

Mortality

Yes

No
55

19

24

58

40

76

10

12

8

90

91

5

2

96

2

1

97

14

19

42

48

10

21

21

76

15

3

4

4

5

93

2

96

\section{$\%$}

56.1

19.4

24.5

59.2

40.8

77.6

10.2

12.2

8.2

91.8

92.9

5.1

2

98

2

1

99

14.3

19.4

42.9

49

10.2

21.4

77.6

15.3

3.1

4.1

5.1

94.9

2

98 
A significant difference was not found between 3-7 and 8-17 age group children concerning trauma rates $(p>0.05)$ (Table 2). The study population consisted of boys (59.2\%) and girls $(40.8 \%)$ without any statistically significant difference in terms of trauma rates ( $p=0.069$; and $p>0.05$, respectively). The affected children fell from a height (77.6\%), injured at a traffic accident (10.2\%) and had an isolated head trauma (12.2\%). Multitrauma was observed in $8.2 \%$ of the cases.

The 0 - 2 age group of patients who were referred to the hospital consisted of nearly equal numbers of boys and girls (49.1\% vs $50.9 \%)$. The corresponding distribution of boys and girls in the age groups of 3-7 (78.9\% vs $21.1 \%)$, and 8-17 $(66.7 \%$ vs $33.3 \%)$ were as indicated in parentheses (Table 3). A statistically significant difference existed between the types of trauma by age groups $(p=0.000 ; p<0.05)$. The difference arises from children in the 0-2 age group. The rate of falling from height in children aged 0-2 years (96.4\%) was significantly higher when compared with 3-7 (57.9\%) and 8-17 (50\%) age groups ( $1=0.000 ; p 1=0.000 ; p 2<0.05)$. There is no significant difference between $3-7$ and $8-17$ age group children in terms of trauma types $(p>0.05)$. There is no statistically significant difference between the sexes in terms of trauma types $(p=0.350 ; p>0.05)$.

Male patients fell from a height in $72.4 \%$, had traffic accidents in $12.1 \%$ and isolated head traumas in $15.5 \%$ of the

Table 2. Distribution of the male and female cases according to their age groups

\begin{tabular}{lcccc}
\hline Gender & $\begin{array}{c}\mathbf{0 - 2} \text { age } \\
\mathbf{n}(\%)\end{array}$ & $\begin{array}{c}\mathbf{3 - 7} \text { age } \\
\mathbf{n ( \% )}\end{array}$ & $\begin{array}{c}\mathbf{8 - 1 7} \text { age } \\
\mathbf{n}(\%)\end{array}$ & $\begin{array}{c}\text { Total } \\
\mathbf{n}(\%)\end{array}$ \\
\hline Male & $27(49.1)$ & $15(78.9)$ & $16(66.7)$ & $58(59.2)$ \\
Female & $28(50.9)$ & $4(21.1)$ & $8(33.3)$ & $40(40.8)$ \\
Total & 55 & 19 & 24 & 98 \\
\hline
\end{tabular}

Table 3. Evaluation of the type of the traumatic event according to age, and gender of the patients

\begin{tabular}{ccccc}
\hline & \multicolumn{3}{c}{ Type of traumatic event } \\
\cline { 2 - 5 } & $\begin{array}{c}\text { Fall from } \\
\text { a height } \\
\mathbf{n ~ ( \% )}\end{array}$ & $\begin{array}{c}\text { Traffic } \\
\text { accident } \\
\text { n (\%) }\end{array}$ & $\begin{array}{c}\text { Isolated } \\
\text { head trauma } \\
\mathbf{n}(\%)\end{array}$ & $\mathbf{p}$ \\
\hline $\begin{array}{c}\text { Age (year) } \\
0-2\end{array}$ & $53(96.4)$ & $0(0)$ & $2(3.6)$ & $0.000^{*}$ \\
$3-7$ & $11(57.9)$ & $4(21.1)$ & $4(21.1)$ & \\
$8-17$ & $12(50)$ & $6(25)$ & $6(25)$ & \\
Gender & & & & \\
Male & $42(72.4)$ & $7(12.1)$ & $9(15.5)$ & 0.350 \\
Female & $34(85)$ & $3(7.5)$ & $3(7.5)$ & \\
\hline
\end{tabular}

Fisher Freeman Halton Test; ${ }^{*} \mathrm{p}<0.05$. cases. Female patients fell from a height in $85 \%$, had a vehicle accident in $7.5 \%$ and isolated head trauma in $7.5 \%$ of the cases. Admission GCS scores ranged from 4 to 15 points (mean \pm SD: $14.63 \pm 1.58$ and median 15 points). According to GCS scores ranging from 4 , and 15 points, the patients had mild (14-15 pts: $92.9 \%)$, moderate (10-13 pts:), and severe ( $<9$ pts: $2 \%$ ) head traumas (Table 4$)$. In $98 \%$ of the children, the pupillary response was isocoric, while in $2 \%$ of them it was anisocoric.

Only one child underwent CPR. Considering the findings of $\mathrm{CT}$, the linear fracture was found in $49 \%$, epidural hematoma in $42.9 \%$, contusion in $21.4 \%$, subdural hematoma in $19.4 \%$, SAH in $14.3 \%$ and a compression fracture in $10.2 \%$ of the cases (Table 1). While $77.6 \%$ of the children did not undergo surgery, hematoma surgery was performed in $15.3 \%$, decompressive surgery in $3.1 \%$, hematoma and decompressive surgery in $4.1 \%$ of the cases. Only $5.1 \%$ of children were hospitalized in the intensive care unit, and two children (2\%) died (Table 1). An inverse and statistically significant correlation was found at a level of $50.5 \%$ between the admission GKS scores and blood glucose levels $(p=0.000 ; p<0.05)$ (Fig. 1).

Table 4. Correlation between admission GCS scores and blood glucose

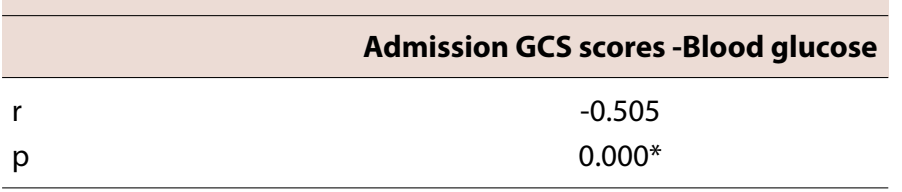

Spearman's rho correlation test; ${ }^{*} \mathrm{p}<0.05$.

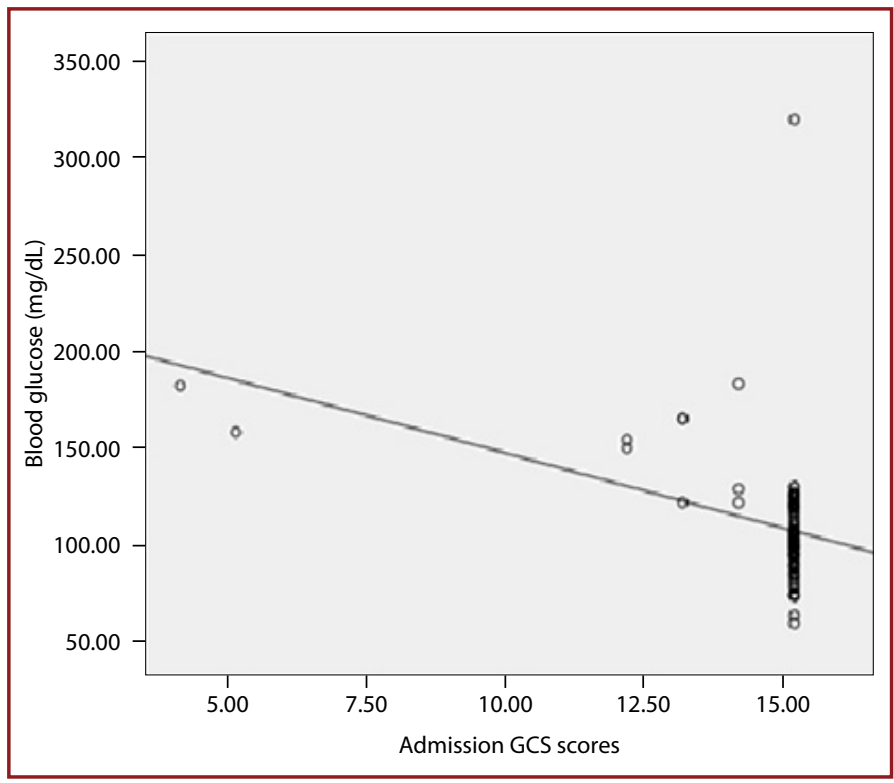

Figure 1. Correlation between the admission GCS scores and blood glucose levels. 


\section{Discussion}

The most important cause of death in the age group of 15 and under is trauma, and head trauma is the most common childhood trauma ${ }^{[5]}$. In $80 \%$ of pediatric age group patients with multiorgan trauma, head trauma is also present ${ }^{[6]}$. According to many studies, it was reported that head traumas are responsible for approximately $50 \%$ of the deaths in the pediatric age group ${ }^{[7]}$. Pediatric head injuries, besides being a serious cause of morbidity and mortality, because of its financial burden it is an important health problem even in developed countries.

Although the causes of pediatric head traumas differ according to age groups, there may also be differences in the ranking of etiological causes among societies. For this reason, demographic studies of societies and even provinces are important. In a study, Cooper et al. identified traffic accidents in $59 \%$, falls from a height in $13 \%$, bicycle accidents in $12 \%$ and other causes in $16 \%$ of the cases of pediatric head trauma ${ }^{[8,9]}$. When grouped by age, they reported falls in $23 \%$, traffic accidents in $49 \%$, bicycle accidents in $7 \%$ and other causes in $19 \%$ of children aged $0-15$ years ${ }^{[9]}$.

In our study, the most common cause of trauma was fall from a height in $77.6 \%$ of the cases followed by traffic accidents and other causes with a rate of $10.2 \%$. However, it should be remembered that there may be etiological differences between the settlements. In a study conducted in Paris, the most frequent reason of falling was falling from the window (72\%), while in the Batman province, falling from the roof (35.5-49.5\%), and in the Samsun province, stumbling on the ground $(70 \%)$ were more frequently observed ${ }^{[10,11,12]}$. The cases we included in our study were between $0-2,3-7$, and $8-17$ years of age in $56.1 \% 19.4 \%$ and $24.5 \%$ of the cases. The most common cause of head trauma in all age groups was again falling $(96.4 \%, 57.9 \%$, $50 \%$, respectively).

Ökten et al. and Şimşek et al. reported that emergency surgery was required in $23.8 \%$, and $18.2 \%$ of their cases, respectively ${ }^{[13,14]}$. In our study, the most common CT finding was a linear fracture and none of them required surgical intervention. Similar to the literature data, we operated $22.4 \%$ of our cases. Hematoma surgery was performed in $15.3 \%$, decompressive surgery in $3.1 \%$, a combination of hematoma and decompressive surgery in $4.1 \%$ of the cases.

In the above-mentioned study, when the patients were evaluated according to their admission GCS scores, moderate and severe head traumas were reported in $16.7 \%$ and $29.9 \%$ of the cases, respectively ${ }^{[13,14]}$. Considering the results of our study, according to the GCS scores, mild, mod- erate, and severe head traumas were detected in $92.9 \%$, $5.1 \%$ and $2 \%$ of the cases, respectively. According to these results, in our study, severe head trauma cases were less frequently encountered compared to the literature data.

Many parameters affecting prognosis after head trauma have been studied. In particular, increased serum glucose values have been reported to be associated with poor prognosis and increased mortality rates after head trauma [15]. Brain injury after head trauma develops through two separate mechanisms, primary and secondary. The primary mechanism of damage is formed by direct compression of the brain due to trauma or hitting on the surrounding tissues ${ }^{[16]}$. The secondary injury mechanism is more complex and develops within hours and days. The role of systemic factors is important in this mechanism.

Hypoxemia, hypotension, hypertension, hyperglycemia and hypoglycemia may be among the effective systemic factors ${ }^{[15,16]}$. Among these, hyperglycemia is the most known systemic factor associated with prognosis. Thus, monitoring and regulation of blood glucose are vital in the follow-up of head trauma patients ${ }^{[15,16]}$. In our study, the blood glucose levels of the patients ranged between 62 and $321 \mathrm{mg} / \mathrm{dl}$ and the median value was $106 \mathrm{mg} / \mathrm{dL}$. There is a statistically significant negative correlation between admission GKS score and blood sugar, which supports the relationship between blood glucose and the clinical condition and prognosis of patients.

\section{Conclusion}

Head injuries are among important public health problems in childhood and may cause severe morbidity and mortality. When we look at the etiology, it is seen that most traumas arise from preventable causes. In our study, the most common cause of trauma was fall from a height, and it was observed that it was more common at younger ages. This is a dismal condition, but fortunately, these traumas can be prevented by taking precautions and training. It has been determined that blood glucose levels seriously affect the prognosis associated with head trauma, and the importance of blood glucose monitoring and regulation is emphasized once again in these patients.

Ethics Committee Approval: Haydarpaşa Numune Training and Research Hospital Chief Physician approved. Date: 03.06.2020 No: 62977262-000-6435.

Peer-review: Externally peer-reviewed.

Authorship Contributions: Concept: M.E., E.A., A.T.Ç.; Design: E.A., M.E.; Data Collection or Processing: M.E., E.A.; Analysis or Interpretation: A.T.Ç., S.T.E., E.A.; Literature Search: S.T.E., E.A.; Writing: E.A. 
Conflict of Interest: None declared.

Financial Disclosure: The authors declared that this study received no financial support.

\section{References}

1. Fulkerson DH, White IK, Rees JM, Baumanis MM, Smith JL, Ackerman LL, et al. Analysis of long-term (median 10.5 years) outcomes in children presenting with traumatic brain injury and an initial Glasgow Coma Scale score of 3 or 4 . J Neurosurg Pediatr 2015;16:410-9. [CrossRef]

2. Kukreti V, Mohseni-Bod H, Drake J. Management of raised intracranial pressure in children with traumatic brain injury. J Pediatr Neurosci 2014;9:207-15. [CrossRef]

3. Choe MC, Gregory AJ, Haegerich TM. What Pediatricians Need to Know About the CDC Guideline on the Diagnosis and Management of mTBI. Front Pediatr 2018;6:249. [CrossRef]

4. Adelson PD, Wisniewski SR, Beca J, Brown SD, Bell M, Muizelaar JP, et al; Paediatric Traumatic Brain Injury Consortium. Comparison of hypothermia and normothermia after severe traumatic brain injury in children (Cool Kids): a phase 3, randomised controlled trial. Lancet Neurol 2013;12:546-53.

5. Emami P, Czorlich P, Fritzsche FS, Westphal M, Rueger JM, Lefering $R$, et al. Impact of Glasgow Coma Scale score and pupil parameters on mortality rate and outcome in pediatric and adult severe traumatic brain injury: a retrospective, multicenter cohort study. Neurosurg 2017;126:760-7. [CrossRef]

6. Haydel MJ, Saeed W. Pediatric Head Trauma. In: StatPearls [Internet]. Treasure Island (FL): StatPearls Publishing; 2020.
7. Ceylan D, Yaldız C, Kızılçay G, Gündüz Y. Head Traumas in Childhood: Retrospective Evaluation of 357 Cases. Türk Nöroşirürji Dergisi 2013;23:255-60.

8. Bensard DD, Mclntyre RC Jr, Moore EE, Moore FA. A critical analysis of acutely injured children managed in an adult level I trauma center. J Pediatr Surg 1994;29:11-8. [CrossRef]

9. Cooper A, Barlow B, DiScala C, String D. Mortality and truncal injury: the pediatric perspective. J Pediatr Surg 1994;29:33-8.

10. Işık A, Gökyar A, Yıldız Ö, Bostancı U, Özdemir C. Çocukluk çağı kafa travmaları, 851 olgunun retrospektif değerlendirilmesi. Epidemiyolojik bir çalışma. Ulus Travma Acil Cerrahi Derg 2011;17:166-72. [CrossRef]

11. Al B, Yildirim C, Coban S. Falls from heights in and around the city of Batman. Ulus Travma Acil Cerrahi Derg 2009;15:141-7.

12. Melo JR, Di Rocco F, Lemos-Júnior LP, Roujeau T, Thélot B, Sainte-Rose $C$, et al. Defenestration in children younger than 6 years old: mortality predictors in severe head trauma. Childs Nerv Syst 2009;25:1077-83. [CrossRef]

13. Ökten Ai, Yalman M, Kaptanoğlu E, Gül B, Gezici AR, Sertel İ. Pediatrik kafa travmaları. Ulusal Travma Dergisi 1996;2:94-9.

14. Simşek O, Hiçdönmez T, Hamamcıoğlu MK, Kılınçer C, Parsak T, Tiryaki M. Pediatric head injuries: A retrospective analysis of 280 patients. Ulus Travma Dergisi 2005;11:310-7.

15. Shi J, Dong B, Mao Y, Guan W, Cao J, Zhu R, et al. Review: Traumatic brain injury and hyperglycemia, a potentially modifiable risk factor. Oncotarget 2016;7:71052-61. [CrossRef]

16. Hale AT, Pekala K, Theobald B, Kelly K, Wolf M, Wellons JC, et al. Predictors of post-discharge seizures in children with traumatic brain injury. Childs Nerv Syst 2018;34:1361-5. [CrossRef] 